\title{
Research on the Artistic Conception of landscape in Chinese Painting
}

\author{
Xiaojing Song \\ Henan Institute of Finance and Banking, Zhengzhou, Henan, China, 450046
}

Keywords: Artistic Conception; Chinese Painting, Landscape Painting

\begin{abstract}
The landscape painting of Chinese traditional painting is as early as 1,000 years than the Western landscape painting, Chinese painting in the landscape of Chinese heavy feelings of precipitation. The "landscape painting mood" of Chinese painting is mainly by describing the nature of mountains and rivers to express a landscape and state of mind. Lyric painter of a kind of ideological feelings, and through the lyrical painting to show the actual situation, the scene blend, the rhythm of life active, so that the works show the charm of endless mood.
\end{abstract}

\section{The Development and Connotation of Artistic Conception in Chinese Landscape Painting}

The Development of Artistic Conception in Chinese Landscape Painting. Chinese artistic conception theory was first used in the criticism and creation of literary works. Tang Dynasty poet Jiao Ran and poet Wang Changling also put forward the "margin" and "take the environment" of the relevant theory, literary theorist Sikong Tu and Liu Yuxi also put forward the "King of the King", "like the elephant" and so further the creation of ideas on the mood.

In the Ming and Qing dynasties, in the creation of literary works and paintings and other fields have around the meaning of the environment and other related issues extensive discussion. Such as the Ming Dynasty art theorist Zhu Cunjie put forward on the painting in the landscape painting "hustle and thunder" and other concepts of the idea, and the Qing Dynasty literary critics and poets Ye Kui also put forward in the creation of Chinese painting process Meaning and the environment should be equal to the idea, he stressed that the creation of Chinese painting landscape painting should be "play the scene" and "Shu write chest" closely together, not only highlight the landscape of natural and can express the creative process of emotion. To the modern aesthetics Wang Guowei and writer Lin Shu also stressed that in the creation of Chinese painting landscape painting "meaning" the importance of Wang Guowei that in the creation of Chinese painting landscape painting process should be subject to creativity, and vigorously promote the creation of works " And pointed out that in the process of painting the creation to highlight the territory of the "no self" of the painting scene, but also to highlight the meaning of the "I have the environment," the aesthetic norms. Therefore, the works of Chinese painting and landscape painting are through this scene and the height of the blend, through the description of time and space portraits to convey the traditional Chinese aesthetic ideas, and continue to make the mood in the Chinese painting landscape painting to play more vividly.

The Connotation of Artistic Conception in Chinese Landscape Painting. In the painting of Chinese painting to constitute the mood must be based on the painting in the space as the basis, through the painting in the process of painting and other paintings to achieve the "meaning and like pass, love and king", through the image blend to achieve the artistic creation of the United States, so as to better achieve the appreciation of the works. The creation of Chinese painting is to create a concrete image of art, more intuitive composition of the structure and expression of artistic conception, so in order to make the painting works can be rid of the painting because of the static and instantaneous expression of the limitations of the mood sex, painters usually through the symbolic and creative painting techniques and painting techniques and through the art of painting language to achieve the painting space expansion and time of the process.

So the painter through the pen to their own to express the feelings of the landscape and the chest 
with the image of the works displayed, so that we can enjoy the works at the same time can feel the rich content of the work. For example, the painting aesthetics of the Tang Dynasty, Zhang Yanyuan put forward in the works of painting to highlight the "conception", in the creation of the work to grasp the "shape to write God", so "Qiyun vivid." The Song Dynasty painter Guo Xi in the creation of Chinese painting landscape painting more prominent painting "heavy meaning" problem, many of his paintings are "meaning", so future generations in the appreciation of his works in the process, there will be a kind of "to the poor" feeling, and he is also the first to "artistic conception" embodied in the meaning of the first place in the painting. And Su Shi's painting, it is more prominent the artistic expression of the painting, because he not only the scene and love into one, but also advocate poetry and art into one of the artistic ideas, so this also appeared in many landscape painting next with the relevant artistic conception of poetry, so that the traditional painting of the landscape painting from the objective image of the creation of a more emphasis on the expression of the subjective spirit, through the painting to achieve care to the situation of the creative tendencies, but also to promote the painting of Chinese painting the development of the artistic conception, and has been constantly enriched and developed so that the Chinese painting painter through the "foreign division of the good fortune, in the heart", so that the Chinese painting landscape in the landscape beauty, natural beauty, artistic beauty, beauty and other aspects of life has been a high degree harmony and unity.

\section{The Artistic Expression Techniques of Chinese Painting Landscape Painting}

The Operation of Ink Skills. Chinese painting landscape painting process of the operation of the painting on the success or failure of this painting will take a crucial role, but also the basis of landscape painting creation, so many times the Chinese landscape painting is also known as ink painting, in the creation of Chinese painting process, the color of ink painting mainly reflects the black ink and white paper, white and black as the main pigment, and ink and water in accordance with the different proportions of deployment, through painting to achieve different visual effects. Therefore, the layout of the landscape painting is more particular about a painting in a different composition of the process of the proportion of the deployment of ink requirements, through the deployment of the appropriate proportion of ink and the use of skilled painting techniques, to be created to outline the scenery, the use of moderate ink color, and through the mix of bright and dark to make the picture more rich three-dimensional and vivid image. Although the color of the ink is relatively simple, but the color of the ink is also more unique, the main ink mainly to the black main tone in the painting through the shades of different colors and reasonable ink color deployment, but also the shape of things can be accurately presented out, giving a visual sense of reality. Therefore, in the process of the creation of Chinese painting landscape painting, can skillfully operate the ink operation skills, the use of good ink color filling technology, and ink halo dyeing skills, can make the landscape painting more elegant and Smart, rhythm stronger, and it can make the painting to express the mood more distant, more prominent the aesthetic value of Chinese painting landscape painting, so the painting of the use of ink painting techniques is one of the important forms of expression of artistic expression.

Chinese painting landscape painting in the ink is usually divided into: black, wet, dry, thick, light and other five, which includes the white paper is also known as the traditional Chinese painting in the basic colors of landscape painting, collectively referred to as Chinese painting landscape painting the painting of the landscape painting in the Chinese painting can be traced back from the period of the Five Dynasties. At that time, some masterpieces of landscape painting put forward the concept of "six" in Chinese painting creation. This is the first time that ink technique has been applied to the painting of Chinese painting. Later, after several generations of painters continue to explore and research, and ultimately create a "ink", "ink", "ink", "dip ink" and other ink techniques, so that the creation of Chinese painting landscape has been greatly enriched. Chinese landscape painting of the artists in the process of painting, but also pay more attention to the creation of blooming method, through the blooming to highlight the artistic conception of the painting. Therefore, in the Chinese painting landscape painting has always been "heavy" history, in the Tang 
Dynasty paintings of Chinese painting, that is, through the adjustment of the proportion of different ink, which formed a thick and heavy color, and through the ink to achieve the painting to express the mood effect, such as In the "picturesque painting" this piece of Chinese painting landscape painting, is through the use of heavy color, the distant mountains, clouds, red, water, near the crane, pine and fishing boats dotted in the river which makes the whole painting movement combination, people have a feeling of immersive and ultimately express the beauty of the art of painting.

Elegant with the Pen Skills. In the process of the creation of Chinese painting landscape painting, many of the outstanding works of Chinese painting landscape painting, pen skills are very elegant, in the creative process with the skill of the pen will help to enhance the expression of landscape painting mood, and elegant use of pen skills Effectively create a superb mood. Therefore, in the creation of Chinese painting landscape painting process, in terms of pen, whether in writing or writing on the pen are relatively high requirements. For example, in the writing skills, to grasp the painting process to mention, press, Dayton, frustrated the exact grasp and distinction, in the pen to pay attention to grasp the pen in the side, side, disease, slow grasp and difference through the use of different skills to create a different style of painting works, such as the Qing Dynasty Shi Tao creation of "Huaiyang Jie Qiu" in the landscape painting, that is, through the full sprinkle of concentrated ink moss point, and the use of Shi Tao unique " Dragging mud with water cracked ", even cracked with rub, shades, wet and dry, with a sharp pen out of the grass, so that the whole picture Xiao Sen Yu Mao, depicting the texture of moist and fertile. Painting in the house with a rough pen, reed with fine pen, the formation of vivid contrast, pale and quiet, embodies a kind of bold and unrestrained magnificent.

The Ingenious of the Spatial Composition. In order to make the artistic conception of the Chinese painting landscape painting more vividly, it is necessary to create a clever space composition of the landscape painting, so that the composition of the drawing paper between the white and the transition between the ink, the interval can be coordinated and integration, both conducive to the painter will be the reality of the scene, the distance can be cleverly combined, but also conducive to the painter through the painting to the painting of the mood to show it vividly. For example, the Ming Dynasty painter Dai Jin's paintings "Spring Hill plot" the whole work with two blocks oblique cut, composition is just right. Close to the rich pine crown as the main body; Zhong Jingshan rock to heavy ink point out of the woods; vision with light ink slightly mountain shape, applied to moss point. Depicting the two mountains cross each other, about tangent, hut faintly about the scene, the visual center of a few sets of vigorous Qiu Song buckling hovering, business. Not only to strengthen the picture of the level of space, but also full of quiet and quiet, so that the whole picture presents a high ancient Qingyuan, leisure and comfort of the literati life taste.

\section{The Artistic Creation of Chinese Landscape Painting}

From ancient times to the present, Chinese literati painters have paid great attention to the art of painting in the landscape painting, and in order to sublimate the mood of the screen and often thought carefully, not only in the operation of ink, pen skills, spatial composition of the study, pay more attention in the process of painting the creation of artistic conception and conception, the image of the selection and composition, so in order to create a picture of the competition, the situation blending, elegant mood of landscape painting, it must be handled "love and king", " and the relationship between love and meaning, and the king, meaning, cleverly integrated into one, and ultimately create a beautiful artistic painting.

The Conception of Artistic Conception. The value of the painting is not related to the conception of artistic conception, but the conception of the artistic conception of the painting is in line with the personal accomplishment, creative idea, painting experience, life experience, creation mood, environment, social environment and so on. There are important links, the painter in preparation for painting, the first painting on the artistic conception of the conception, for the creation of elegant mood of the Chinese painting landscape map to prepare, a lot of time, this stage of the mood conception concept is done in the mind, the first painting will be through the collection of material through the mind for processing, get a want to express a more complete artistic image, 
the idea of painting is also the idea of painting the artist's painting process. In general, the themes of the paintings that are determined by the conception of the artistic conception of the artist include: a variety of forms such as a strong subject class, a beautiful subject class, a quaint theme class, a minimalist subject class, and a subject once, you can enter into the selection stage of the image.

The Choice of Image. In the process of the selection of the image of the painting of the Chinese painting, the image of the landscape painting is mainly expressed by the subject of the painting, and the image of the landscape painting plays an important role in the communication process of the landscape painting. The theme of the landscape painting is mainly the painting of the natural landscape the main and supplemented by some car horses, characters, houses embellishment. Because of the ever-changing nature, the idea of the artist's conception of the artistic conception must also change with the four seasons of nature, and it is also because the landscape of the landscape is changing so that the image of the landscape painting is more rich and varied. Therefore, the painter in the painting process needs for the choice of the image and the combination of careful selection, so that excellence, in order to create elegant artistic painting.

The Composition of the Image. After choosing the image of the painting, it is necessary to make a clever composition of the image of the painting, so that the painting works in the composition of a certain law and laws, such as in the painting to highlight the layout of the distance, the combination of the actual situation and so on, in the composition cannot be casually portrayed, but through the image of communication to highlight the theme of painting, and art processing techniques, the image cleverly presented in the painting works, so in the painting process, different images of the composition shown by the different context to achieve the effect of different moods.

\section{Conclusion}

The artistic conception of Chinese painting landscape painting is one of the important symbols to measure the artistic value and aesthetic value of the painting. In order to reflect the beauty of the artistic conception in the process of the creation of the landscape painting, it is necessary to improve the painting technique, skills, painting works of the spatial composition of clever and other aspects of the painting in the creation of painting skills, through the skill of painting to be able to express the painting scene to show the picture to the picture. Of course, a high artistic value of the landscape painting also need to continue to improve their own aesthetic concepts and artistic accomplishment, through the painting process of artistic conception, image selection and composition of the final creation of a picture of the game, elegant artistic landscape painting works, so that works to "love and king", "king and Italy", "love and meaning" harmonious blend, and ultimately create elegant artistic painting.

\section{References}

[1] Liu Lu. A Comparative Study on the Artistic Conception of Chinese Landscape Paintings in the Song Dynasty[J]. Qufu Normal University, 2013

[2] Zhang Jing. The Artistic Conception of Chinese Painting Art[J]. Yalu River (the second half of the month), 2014 (06)

[3] Yao Qinghua. Modern packaging design of the traditional ink language language reference and combination[J]. Packaging Engineering, 2014 (16)

[4] Ma Gengyun. Traditional ink and contemporary ink in the advertising posters in the visual tension of the study[J]. Packaging Engineering, 2014 (20)

[5] Hao Li. Analysis of the art of artistic expression of artistic changes [J]. Chinese off-campus education (late), 2012 (05) 